Kocaeli Journal of Science and Engineering

\title{
Numerical Examination of Heat Transfer Augmentation between the Plates with Square Cross-Sectional Ribs for the Staggered Arrangement
}

\author{
Ilker Goktepeli $^{1, *}$ iD, Ulas Atmaca ${ }^{2}$ iD \\ ${ }^{1}$ Department of Mechanical Engineering, Konya Technical University, Konya, 42075, Turkey, ORCID: 0000-0002-2886-8018 \\ ${ }^{2}$ Department of Mechanical Engineering, Konya Technical University, Konya, 42075, Turkey, ORCID: 0000-0002-9265-1446
}

\section{Article Info}

Research paper

Received : December 10, 2019

Accepted : October 15, 2020

\begin{abstract}
Heat transfer enhancement in the ducts is significantly related with flow separation and reattachment regions. Therefore, ribs are used to obtain the rotational flows in the vicinity of the wall since the fluctuations in the thermal and hydrodynamic boundary layers are effective for the increment of heat transfer by convection. Even though heat transfer surface area is enlarged by placing the ribs into the channels, the pressure loss due to the ribs has to be taken into account and controlled in these systems. Based on the aforementioned explanations, the square cross-sectional ribs have been mounted on the bottom and the top walls of horizontal parallel plates in terms of staggered arrangement. In the present paper, numerical analyses have been conducted via $k-\omega$ SST turbulence model at $\operatorname{Re}=10000,15000$ and 20000 for different spacing values between two successive ribs. For the constant rib dimensions, the ribbed models have been compared by referring to smooth plates as reference model. For this reason; time-averaged results including streamwise velocity components, temperature distributions, pressure values, streamline patterns and Nusselt numbers for the ribbed and the smooth plates have been separately presented and compared. Heat transfer has been enhanced due to the ribs deforming the hydrodynamic and thermal boundary layers. Furthermore, increasing the rib spacing and Reynolds number has enhanced Nusselt number. As observed, heat transfer has also been augmented by extending the distance between two successive ribs since fluid easily penetrates to the sink between them for the production of recirculation regions. However, in case of the ribbed models, there are gradual drop pressure values along the channel. For this reason, the rib effect on these values is much more as evidently observed at $\operatorname{Re}=10000$.
\end{abstract}

\section{Introduction}

Heat transfer augmentation via passive methods is an important subject in the engineering. The power expenditure reduction of the system is considered when it comes to improve thermal performance.

Even though high-performance cooling or heating units requiring less cooling working fluid are aimed in the design process, momentum and heat transfer in ribbed channels is not a straightforward problem as expected [1]. The main target is to enhance the amount of convective heat transfer by implementing various techniques. All

\footnotetext{
* Corresponding Author: igoktepeli@ktun.edu.t
}

passive techniques are almost applied by extending the wetted surface area via artificial surface elements. Moreover, it is done by breaking of both hydrodynamic and thermal boundary layers. In this context, a rib is a surface element to increase both heat transfer and turbulence intensity. A method for passive heat transfer enhancement has been carried out [2] to disrupt velocity and temperature profiles near to the plates for the generation of recirculation regions around the surface elements. It is known that the vortices lean to move by tracking swirling paths causing the fluid displacement between the core regions and the plates [3]. Thus, the amount of heat transfer via convection is augmented by directing more fresh fluid onto the plates [4]. Local heat transfer coefficient is increased as stated in these cases. In 
this study, for this reason, the square ribs have been mounted on the plates. Although various kinds of vortex generators were used in the previous studies [5-8], the rectangular element is one of the most frequently used ribs. Since the rib shape is important for the effect of heat transfer enhancement, its orientations and arrangements are accepted as effective on the thermal performance. As explained [9], the rib shape and its arrangement cause the separation bubble and the fluctuations related with the turbulent kinetic energy. On that account, staggered arrangement has been preferred in the present study. The staggered ribs have been placed on the plates to improve the thermal efficiency as in the similar approach proposed [10]. Staggered rib configuration is feasible for the thermal systems requiring periodical flow conditions as discussed [11]. Successive studies including the staggered arrangement with the rectangular cross-sectional ribs have been done [12-16]. In some studies [17-20], the staggered arrangement has been contrasted with the symmetrical one. Accordingly, the aim of this numerical study is to investigate heat transfer enhancement between the plates in terms of the staggered arrangement.

\section{Numerical Method}

\subsection{Boundary and Initial Conditions}

In this study, the square cross-sectional ribs have been mounted on the plates by considering the staggered arrangement. Heat transfer enhancement owing to the ribs has been investigated via $\mathrm{k}-\omega$ SST turbulence model for two-dimensional analyses between the horizontal plates. ANSYS Fluent 18.0 has been used for the numerical analyses. One of the ribbed models used has been presented in Figure 1.

The channel height, $\mathrm{H}$, is $0.05 \mathrm{~m}$. The hydraulic diameter is $\mathrm{D}_{\mathrm{H}}=2 \mathrm{H}$. All dimensions have been normalized with the duct height, $\mathrm{L}^{\prime}=\mathrm{L} / \mathrm{H}=20$, as done for the length of the channel. The height and the width of the rib are shown as $h^{\prime}=h / H=0.1$ and $w^{\prime}=w / H=0.1$, respectively, which are constant for this study. The spacing between two ribs on the same plate is from $\mathrm{S}^{\prime}=\mathrm{S} / \mathrm{H}=0.5$ to 1 . Moreover, the rib on any plate has been centered with respect to the two successive ribs of the opposite plate as indicated in Figure 1. The ribs have been mounted after L' $=10$ for the flow development [21]. Four models have been used in the present study.

Heat transfer and turbulent flow characteristics between the horizontal plates have been numerically investigated for $10000 \leq \operatorname{Re}=U_{\infty} D_{H} / v \leq 20000$ where the inlet velocity values are $0.1 \mathrm{~m} / \mathrm{s} \leq \mathrm{U}_{\infty} \leq 0.2 \mathrm{~m} / \mathrm{s}$. Thermophysical properties of fluid flow have been assumed to be constant for the numerical analyses.

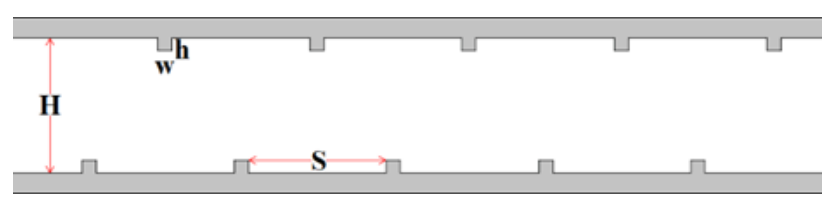

Figure 1. The schematic of the model.

Four models have been formed for the numerical analyses. In the next step, it is needed to attain the proper grid structure for the solution process. The boundary conditions for the study have been given in Figure 2 . Uniform velocity which is normal to the boundary has been used at the inlet of the channel. Pressure outlet with gauge pressure of zero has been defined at the outlet which is open to atmosphere. In the regions where the fluid contacts the wall, no-slip boundary condition has been applied. For the smooth plate, in the case that no rib is used, wall boundary condition is identified for the plates. In case of the ribbed plate, the same boundary condition has been implemented for surfaces having the ribs which are in contact with the fluid.

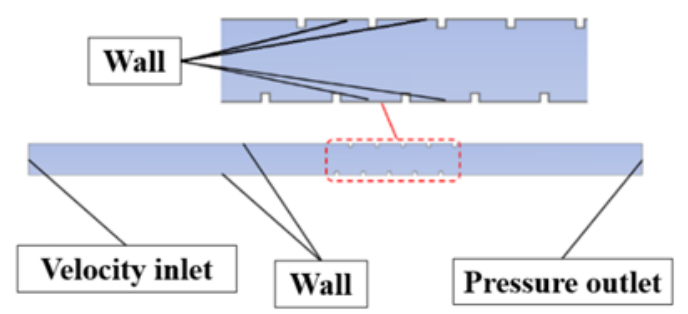

Figure 2. Boundary conditions.

Due to the incompressible flow, pressure-based solver has been utilized. Semi-Implicit Method for PressureLinked Equations (SIMPLE) scheme has been used for the pressure-velocity coupling.

\subsection{Grid Structure}

Various parameters are related with generation of the grid structure. In this manner, a correlation for the smooth plate has been considered for the comparison with the numerical result as given in Eq. (1) [22]. The solution has to be independent of the grid structure.

$N u=0.021 \operatorname{Pr}^{0.5} \operatorname{Re}^{0.8}$

As a result of this correlation, Nusselt number has been calculated as $\mathrm{Nu}=84.19$ at $\mathrm{Re}=10000$. Firstly, the results of the smooth plate have been compared with the result of the correlation for $\mathrm{Re}=10000$ via four turbulence models. Exemplarily, the results of the turbulence models 
have been presented in Table 1. The closest result to the result of the correlation has been obtained by k- $\omega$ Shear Stress Transport (SST) turbulence model. The second one was standard k- $\omega$ turbulence model. Although better results have been acquired via two k- $\omega$ turbulence models, $k-\omega$ SST turbulence model has been approved because of the nearest result to the correlation result. Furthermore, the numerical analyses including smooth plates have been verified by comparing the Nusselt numbers with the ones of the considered correlation. After the validation of the results, the numerical analyses for the ribbed plates have been maintained and then completed.

Table 1. Prototype electric vehicle parameters.

\begin{tabular}{|l|l|}
\hline Turbulence model & Nu \\
\hline k- $\varepsilon$ Realizable & 97.63 \\
\hline k- $\varepsilon$ Re-Normalization Group (RNG) & 115.37 \\
\hline k- $\omega$ Shear Stress Transport (SST) & 86.43 \\
\hline k- $\omega$ Standard & 87.55 \\
\hline
\end{tabular}

Nusselt numbers have been found via k- $\omega$ SST turbulence model based on different grid numbers as shown in Table 2. Even though the results were very close to each other for all grid structures, the nearest result with regard to the correlation has been provided via the grid number of $6.6 \times 10^{5}$.

Table 2. Nusselt numbers attained for different grid numbers via $\mathrm{k}-\omega \mathrm{SST}$ turbulence model at $\operatorname{Re}=10000$.

\begin{tabular}{|l|l|}
\hline Grid number & Nu \\
\hline $3 \times 10^{5}$ & 87.01 \\
\hline $4.3 \times 10^{5}$ & 86.46 \\
\hline $6.6 \times 10^{5}$ & 86.43 \\
\hline $8.6 \times 10^{5}$ & 86.52 \\
\hline $1.16 \times 10^{6}$ & 86.53 \\
\hline
\end{tabular}

The skewness (maximum value $\leq 0.95$ ) and the orthogonal quality (minimum value $\geq 0.15$ ) values have been obtained as in the suggested intervals [23]. A meshed model has been indicated with the detailed views in Figure 3.

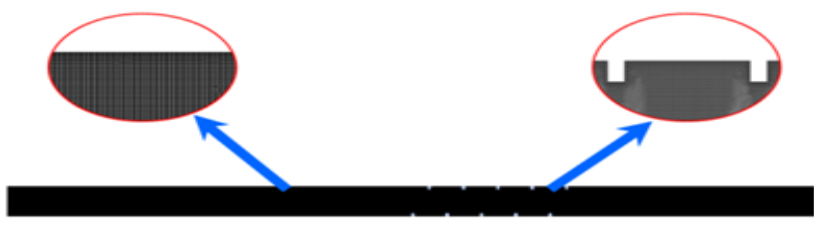

Figure 3. The meshed model given as an example.

Thinner grid elements have been formed in the walls containing the ribs to take the boundary layer effect into account. Edge sizing for the grid structure has been used and the total thickness inflation has been applied for the first ten layers.

\subsection{Equations}

Based on the number of the grid structure and the proper turbulence model determined for the present study, all numerical analyses have been conducted with the software solver. It is needed to underscore that the solver equations are very crucial in the background. In the flow modeling, continuity and momentum equations have been solved. In case of the turbulent flow, Reynolds-Averaged Navier-Stokes (RANS) equations are obtained with the time-averaged versions of these equations. For the incompressible flow condition, the continuity and the momentum equations have been given with Eqs. (2-3, respectively [23]. In these equations, $\mathrm{k}$ stands for the turbulent kinetic energy and $\omega$ represents the specific dissipation rate. Moreover, $\widetilde{G}_{k}$ is the generation of the turbulent kinetic energy owing to the average velocity gradients while $G_{\omega}$ is defined as the generation of the specific dissipation rate. The effective diffusivity values of $\mathrm{k}$ and $\omega$ are symbolized with $\Gamma_{\mathrm{k}}$ and $\Gamma_{\omega}$ terms. Also, $\mathrm{Y}_{\mathrm{k}}$ and $\mathrm{Y}_{\omega}$ are the dissipation of $\mathrm{k}$ and $\omega$ due to turbulence. The cross-diffusion term is given by $D_{\omega}$ while $S_{k}$ and $S \omega$ are the user-defined source terms.

$\frac{\partial \overline{u_{l}}}{\partial x_{i}}=0$

$\frac{\partial \bar{u}_{i}}{\partial t}+\frac{\partial\left(\bar{u}_{i} \bar{u}_{j}\right)}{\partial x_{j}}=-\frac{1}{\rho} \frac{\partial \bar{p}}{\partial x_{i}}-\frac{\partial \tau_{i j}}{\partial x_{j}}+\frac{\partial}{\partial x_{j}}\left(v \frac{\partial \bar{u}_{i}}{\partial x_{j}}\right)$

Energy equation, presented in Eq. (4), is solved for the heat transfer problems [23]:

$\frac{\partial}{\partial t}(\rho E)+\frac{\partial}{\partial x_{i}}\left[u_{i}(\rho E+p)\right]=\frac{\partial}{\partial x_{j}}\left[\left(k+\frac{C_{p} \mu_{t}}{P_{t_{t}}}\right) \frac{\partial T}{\partial x_{j}}+u_{i}\left(\tau_{i j}\right)_{e f f}\right]+S_{h}$

Additional terms, the turbulent stresses, have to be included in the solution procedure enabled by the turbulence model. The equations used in the turbulence model have been presented in Eqs. (5-6) [23]:

$$
\begin{aligned}
& \frac{\partial}{\partial \mathrm{t}}(\rho \mathrm{k})+\frac{\partial}{\partial \mathrm{x}_{\mathrm{i}}}\left(\rho \mathrm{ku}_{\mathrm{i}}\right)=\frac{\partial}{\partial \mathrm{x}_{\mathrm{j}}}\left[\Gamma_{\mathrm{k}} \frac{\partial \mathrm{k}}{\partial \mathrm{x}_{\mathrm{j}}}\right]+\widetilde{\mathrm{G}}_{\mathrm{k}}-\mathrm{Y}_{\mathrm{k}}+\mathrm{S}_{\mathrm{k}} \# \\
& \frac{\partial}{\partial \mathrm{t}}(\rho \omega)+\frac{\partial}{\partial \mathrm{x}_{\mathrm{i}}}\left(\rho \omega \mathrm{u}_{\mathrm{i}}\right)=\frac{\partial}{\partial \mathrm{x}_{\mathrm{j}}}\left[\Gamma_{\omega} \frac{\partial \omega}{\partial \mathrm{x}_{\mathrm{j}}}\right]+\mathrm{G}_{\omega}-\mathrm{Y}_{\omega}+\mathrm{D}_{\omega}+\mathrm{S}_{\omega} \#
\end{aligned}
$$

In the numerical analyses, the time step was $0.0068 \mathrm{~s}$ and maximum twenty iterations per time step have been done. Nonetheless, the total number of the iterations 
changes with the required analysis duration depending on the residuals of the equations as $10^{-8}$ for all analyses. As a result, the dimensionless wall distance has been provided as $\mathrm{y}^{+}=\mathrm{u}^{*} \mathrm{y} / \mathrm{v} \cong 1$ and matched with the criteria.

\section{Results and Discussion}

Heat transfer characteristics attained by performing the numerical analyses between the parallel plates have been presented for $10000 \leq \mathrm{Re} \leq 20000$ in Figures 4-7. These considered characteristics have been given for timeaveraged results of temperature $\langle\mathrm{T}\rangle$ and pressure $\langle\mathrm{P}\rangle$ distributions, streamwise velocity components $\langle\mathrm{u}\rangle$ and streamline patterns $\langle\Psi\rangle$. Mean Nusselt number values $\mathrm{Nu})$ have also been given in Figure 8.

Time-averaged results of temperature $\langle\mathrm{T}\rangle$ distributions have been attained as a result of the numerical analyses and indicated in Figure 4. Fluid at $300 \mathrm{~K}$ has been assumed to enter the duct and its plates were at $400 \mathrm{~K}$. The maximum and the minimum values were as $400 \mathrm{~K}$ and 300 $\mathrm{K}$, respectively for the problem including the single-phase flow. Since the temperature distributions have been differently obtained for different ducts, changes of the heat transfer characteristics are clearly observed. However, there is less effect of the smooth plate on heat transfer as compared to that of the ribbed models. This is due to temperature variation observed close to the wall. In this case, heat transfer is enhanced by increasing Reynolds number since heat transfer coefficient is augmented as a result of the increment of the flow rate. For this reason, the rib effect on the heat transfer characteristics is much more. Due to the interaction between fluid flow and ribs, there is flow separation owing to the first one. As mentioned before, heat transfer enhancement is done since increasing Reynolds number causes the increment of heat transfer coefficient. This is explained by the breaking of hydrodynamic and thermal boundary layers because of the ribs. In these regions, the sudden temperature changes are observed due to chaotic flow. Heat transfer has been considerably increased as stated. This mentioned situation has been observed for all cases. Increase in fluid temperature has been provided along the centerline of the duct owing to the increment of the rib heights. Moreover, heat transfer surface area has been enlarged by the ribs. This also causes augmentation of heat transfer. Though mounting the higher rib to increase the influence of the flow separation in terms of the heat transfer augmentation, the rib height is restricted by the distance between the opposite plates. What is more, pressure loss has to be considered in the design of the heat transfer equipment. In such condition, as an alternative parameter, the spacing between the ribs is taken into account for heat transfer enhancement. As observed from the results, heat transfer has been enhanced by enlarging the gap between two successive ribs since fluid easily penetrates to the space between them for the production of recirculation regions. This aforementioned situation has been seen from the temperature change as given in Figure 4. Increasing the spacing between the ribs also extends the contact area for the fluid after the flow reattachment. In case of narrow spacing between the ribs, it is challenging for the fluid to enter to the zone between the ribs. It can be seen from Figure 4 that only one circulation zone occurs when the ribs are closer enough to each other. While the distance is increased, two circulation zones can be seen and this phenomenon increases the heat transfer coefficient. The temperature contours (Figure 4) and streamline distributions (Figure 7) exhibit similar patterns as can be seen from the aforementioned graphics.

Time-averaged results of pressure distributions have been given in Figure 5 as a result of the numerical analyses performed. Pressure loss for the smooth plate was less than the ribbed model as expected for all Reynolds numbers. In case of the model with no ribs, there is gradual drop observed for pressure values along the channel as anticipated again. However, pressure loss values have increased because of increasing Reynolds number. In the meantime, placing the ribs on the plates also triggers the pressure drop. For the same rib spacing, increase in Reynolds number causes pressure loss as observed. By keeping Reynolds number constant at $\operatorname{Re}=10000$, there is not much change observed in pressure values for different rib spacing values. However, pressure loss has been triggered by increasing the spacing between the ribs for Reynolds numbers of $\operatorname{Re}=15000$ and $\operatorname{Re}=20000$. Moreover, there is sharp decrement in pressure seen for all cases with the ribbed plates. This region that sudden decrease of pressure values occurred is generally the wake of the first rib on the upper plate. Especially, this is the minimum pressure region for $\mathrm{S}^{\prime}=0.5$ at $10000 \leq \mathrm{Re} \leq$ 20000. When the rib spacing was gradually increased, the additional minimum pressure zones have been observed in the wake regions of different ribs depending on their position. After the second ribs, pressure values have increased and approached to the mean values of the legend bar. Temporary recovery for pressure values has been attained. This situation is related with the decrease of flow rate after the second ribs. The recovery in pressure occurred earlier for the cases of $S^{\prime}=0.5$ and kept its disposition until the outlet of the ribbed region. However, there is again a decrement for pressure in the vicinity of the last rib on the lower plate. After the ribbed region passed, mean pressure values have been provided.

Time-averaged results of streamwise velocity components $\langle\mathrm{u}\rangle$ have been indicated in Figure 6. For the 
smooth plates, the maximum values of the velocity components have been obtained at the exterior region of boundary layer. Due to no-slip condition on the wall, there is decrease in the velocity components in the regions under the thumb of boundary layer. Since there are no turbulators on the plates, rotational flow has not been acquired. As can be seen from the charts, the cross-sectional flow area of the channel is minimized owing to the ribs placed on the plates. These ribs have caused the flow separation as well as rotational flow. For this reason, negative velocity values have been obtained in terms of the ribbed ducts. Therefore, there is an increment for the streamwise velocity components observed due to the increment of the rib height values. This phenomenon is explained via flow separation owing to the first rib on both plates. Due to the staggered rib arrangement, asymmetrical flow patterns have been observed. In case of the forward-facing step flow where after the flow separates from the walls, it reattaches to the upstream corner of the rib and it is again separated from that point. In the regions where flow is separated, the rotational flows have been seen at the upstream of the rib. This is identified as the forward-facing step flow in the front of the rib, the cavity flow between two successive ribs and the backward-facing step flow in the wake region of the rib [24]. In terms of the cavity flow; rotational flow, which is more energetic between the first two ribs relatively, has lost its influence between the other ones. For most of the cases, the regions where the maximum values attained in were the sinks bounded by the first two ribs and the upper side of the centerline. However, there is not much change for the streamwise velocity components while the margin between the ribs is widened. The region that the maximum values are achieved has also been sighted between the other ribs depending on increment of rib spacing.

Time-averaged results of streamline patterns $\langle\Psi\rangle$ have been given in Figure 7 as a result of the numerical analyses performed. In terms of the smooth plates, uniform flow has been observed since there are no additional elements diminishing the flow. In the presence of the ribs, rather chaotic flow structure has been obtained. Flow structure has changed with increasing rib spacing. Rotational flow has been seen between first two ribs in a row due to flow separation considerably affected by them. Since the leading element to distort the flow was the first rib, larger vortices have been attained in the wake of the first one for both plates. The separated flow produces a lower pressure region at the downstream of the first ribs as in Figure 7. Periodical flow has been seen because of the rib arrangement; the intensity of eddies was less than the first ones. What is more, the required distance for the flow recovery is approximately constant for the rib spacing and Reynolds number.

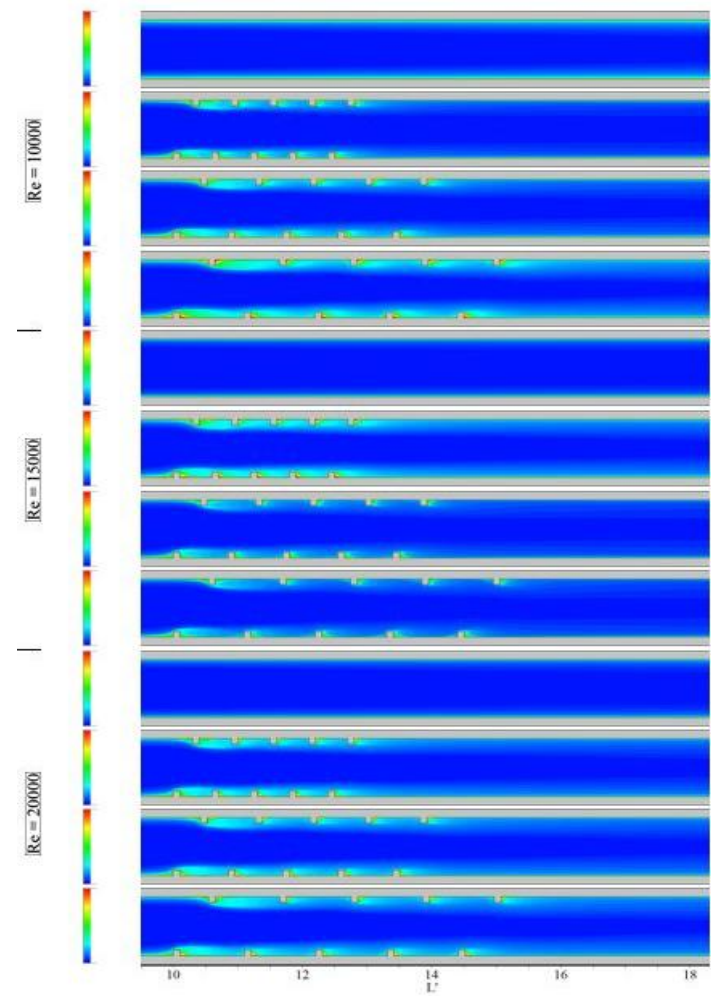

Figure 4. Time-averaged results of temperature distributions $\langle\mathrm{T}\rangle$ for the ducts at $\operatorname{Re}=10000,15000$ and 20000 .

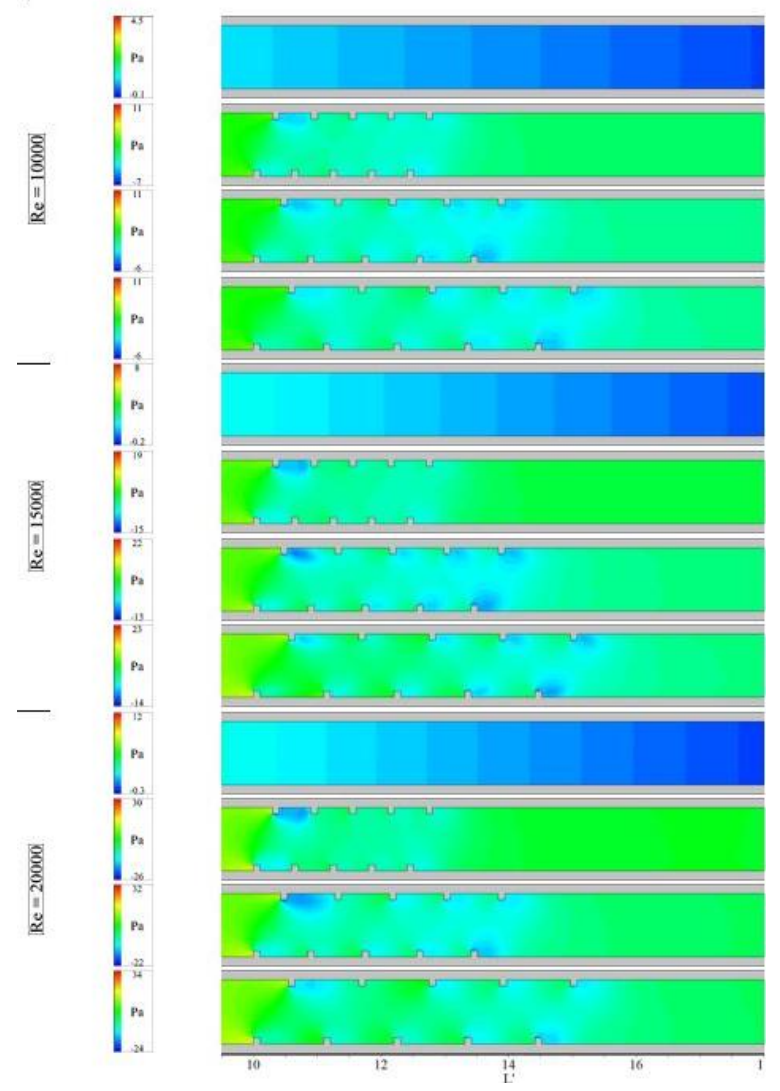

Figure 5. Time-averaged results of pressure distributions $\langle\mathrm{P}\rangle$ for the ducts at $\mathrm{Re}=10000$, 15000 and 20000 . 


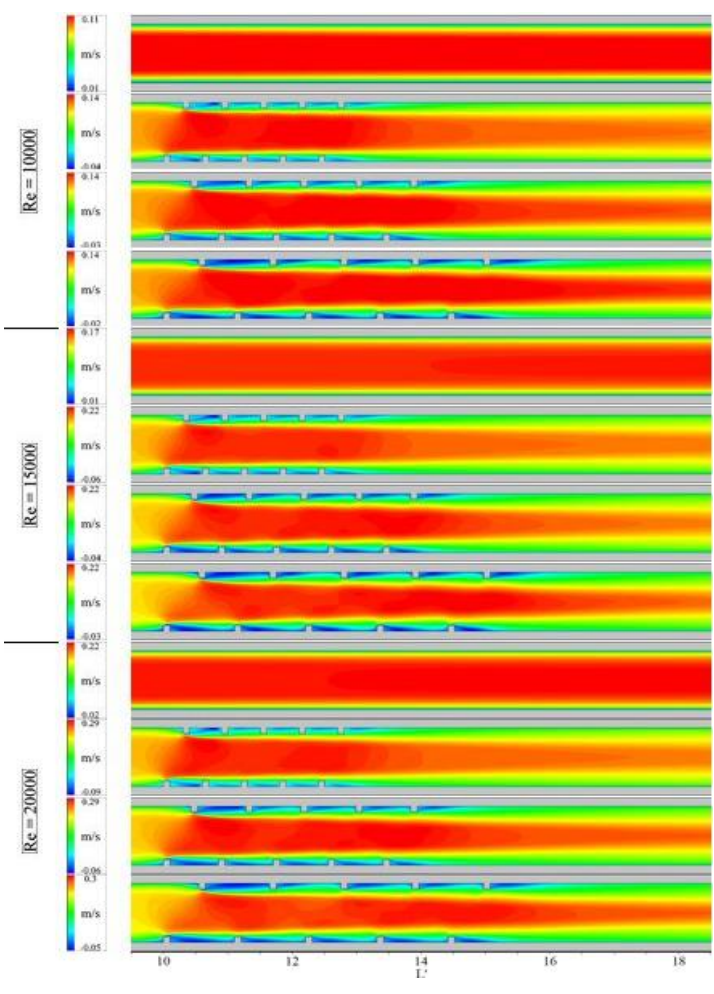

Figure 6. Time-averaged results of streamwise velocity components $\langle\mathrm{u}\rangle$ for the ducts at $\operatorname{Re}=10000,15000$ and 20000 .

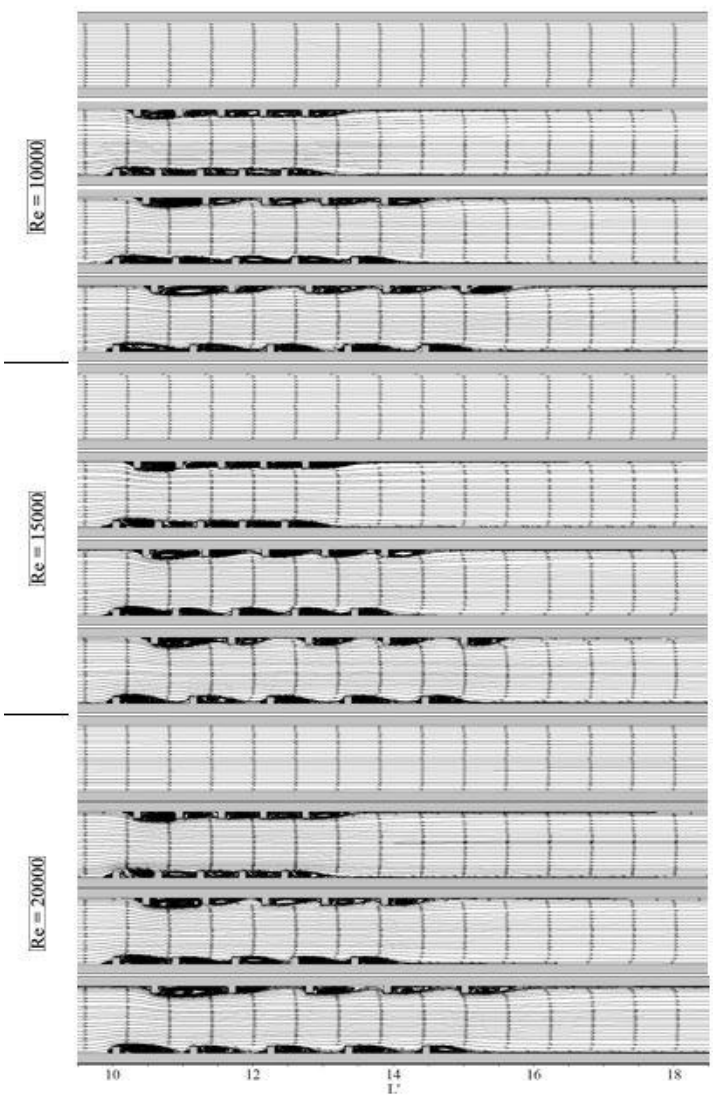

Figure 7. Time-averaged results of streamline patterns $\langle\Psi>$ for the ducts at $\operatorname{Re}=10000$, 15000 and 20000 .
Time-averaged results of mean Nusselt number values for the ribbed plates have been normalized with the values of Nusselt number of the smooth plates. These comparison charts have been presented in Figure 8 for all cases.

With respect to these graphics, Nusselt numbers have been increased by mounting the ribs on the plates. By extending the distance between two successive ribs, mean Nusselt numbers have also been increased. However, the rib effect on Nusselt number values is much more as clearly seen for $\mathrm{Re}=10000$. This effect has gradually been decreased for increasing Reynolds numbers.

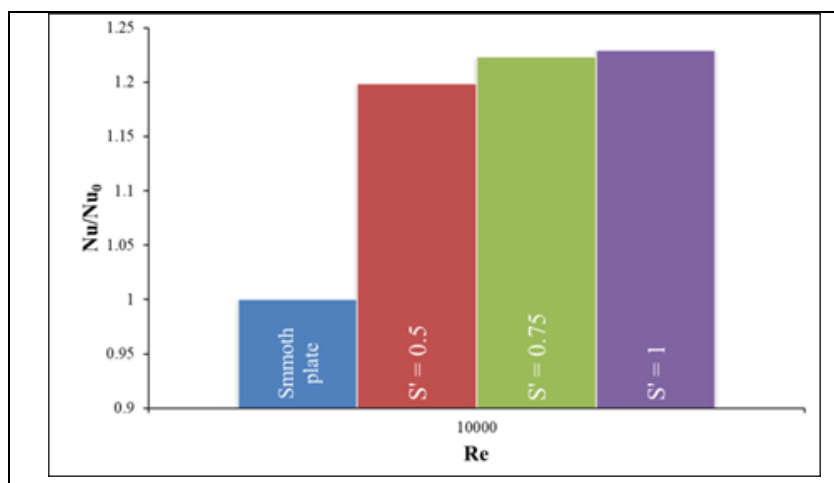

(a)

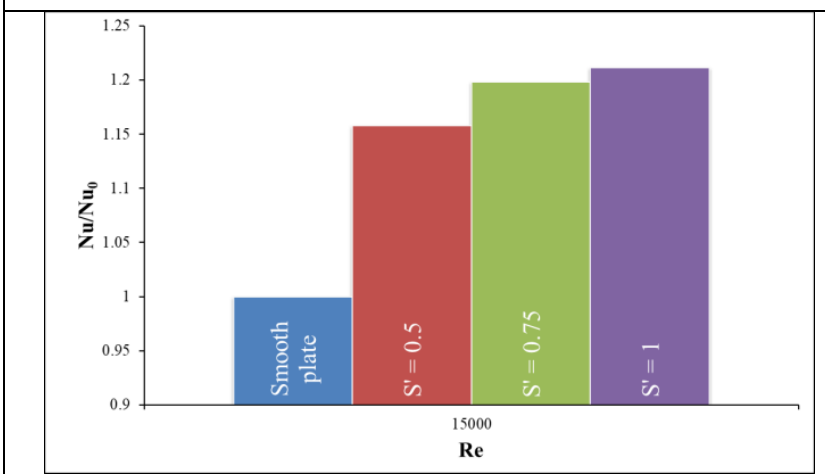

(b)

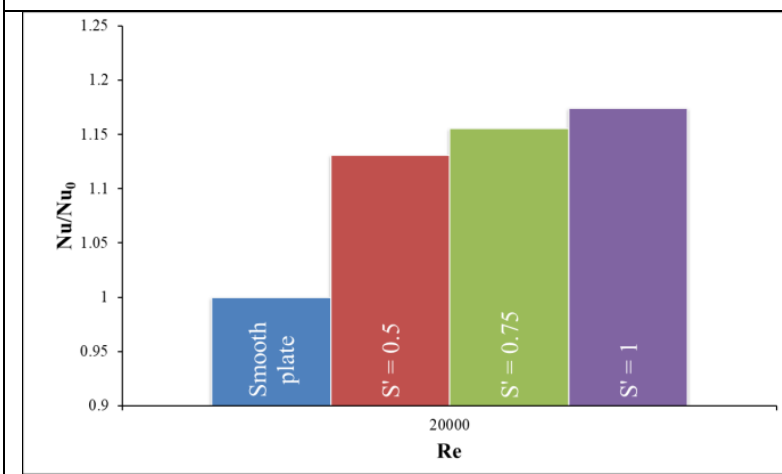

(c)

Figure 8. Time-averaged and normalized results of mean Nusselt number values for (a) $\operatorname{Re}=10000$, (b) 15000 and (c) 20000 


\section{Conclusions}

Heat transfer and turbulent flow characteristics between the plates have been numerically examined by considering the influence of the square cross-sectional ribs at $10000 \leq \mathrm{Re} \leq 20000$ for the staggered arrangement in the present study. For the constant streamwise rib width of $\mathrm{w}^{\prime}=0.1$, the dimensionless spacing have been varied as 0.5 $\leq \mathrm{S}^{\prime} \leq 1$, respectively. All concluding remarks have been given by the following statements:

- For the smooth plates, heat transfer has only been enhanced owing to the increment of Reynolds number. For this reason, the heat transfer coefficient between the fluid and the plates has been increased.

- For the ribbed plates, more turbulent flow structure has been observed as compared to that of the case including no rib. This result is expressed by the deformation of hydrodynamic and thermal boundary layers because of the ribs on the plates.

- Increasing the rib spacing and Reynolds number has enhanced Nusselt number.

- Pressure loss for the case of smooth plate was less as expected for all Reynolds numbers. In case of the ribbed models, there are gradual drop pressure values along the channel. However, pressure loss values have increased because of increasing Reynolds number. In the meantime, placing the ribs on the plates also triggers the pressure drop.

- For most of the cases; the regions where the maximum values obtained in were the sinks bounded by the first two ribs and the upper side of the centerline. However, the margin between the ribs has almost no effect on the streamwise velocity components.

- As observed, heat transfer has also been augmented by extending the distance between two successive ribs since fluid easily penetrates to the sink between them for the production of recirculation regions.

- Average Nusselt numbers have been enhanced by the ribs on the plates. It has also been done by enlarging the gap between the ribs. However, the rib effect on these values is much more as evidently observed at $\mathrm{Re}=10000$. This effect has gradually been decreased for increasing Reynolds numbers.

\section{Acknowledgements}

The authors would like to acknowledge the funding of Academic Staff Training Program (OYP) for Project No. of 2018-OYP-046.

\section{References}

[1] Sundén B., 2011. Convective Heat Transfer and Fluid Flow Physics in Some Ribbed Ducts Using Liquid Crystal Thermography and PIV Measuring Techniques. Heat and Mass Transfer, 47(8), pp.899-910.

[2] Alfarawi S., Abdel-Moneim S., Bodalal A., 2017. Experimental İnvestigations of Heat Transfer Enhancement From Rectangular Duct Roughened by Hybrid Ribs. International Journal of Thermal Sciences, 118, pp.123-138.

[3] Tiggelbeck S., Mitra N.K., Fiebig M., 1993. Experimental İnvestigations of Heat Transfer Enhancement and Flow Losses in A Channel with Double Rows of Longitudinal Vortex Generators. International Journal of Heat and Mass Transfer, 36(9), pp.2327-2337.

[4] Abdollahi A., Shams M., 2015. Optimization of Shape and Angle of Attack of Winglet Vortex Generator in A Rectangular Channel for Heat Transfer Enhancement. Applied Thermal Engineering, 81, pp.376-387.

[5] Sripattanapipat S., Promvonge P., 2009. Numerical Analysis of Laminar Heat Transfer in A Channel with Diamond-Shaped Baffles. International Communications in Heat and Mass Transfer, 36(1), pp.32-38.

[6] Manca O., Nardini S., Ricci D., 2011. Numerical Analysis of Water Forced Convection in Channels with Differently Shaped Transverse Ribs. Journal of Applied Mathematics 2011, 323485.

[7] Ahmed M., Yusoff M., Shuaib N., 2013. Effects of Geometrical Parameters on The Flow and Heat Transfer Characteristics in Trapezoidal-Corrugated Channel Using Nanofluid. International Communications in Heat and Mass Transfer, 42, pp.69-74.

[8] Aslan E., Taymaz I., Islamoglu Y., 2016. Finite Volume Simulation for Convective Heat Transfer in Wavy Channels. Heat and Mass Transfer, 52(3), pp.483-497.

[9] Moon M.A., Park M.J., Kim K.Y., 2014. Evaluation of Heat Transfer Performances of Various Rib Shapes. International Journal of Heat and Mass Transfer, 71, pp.275-284.

[10] Kaewkohkiat Y., Promvonge P., Eiamsa-Ard S., 2017. Turbulent Periodic Flow and Heat Transfer in A Rectangular Channel with Detached V-Baffles. Journal of Engineering Thermophysics, 26(4), pp.542-552. 
[11] Patankar S., Liu C., Sparrow E., 1977. Fully Developed Flow and Heat Transfer in Ducts Having Streamwise-Periodic Variations of Cross-Sectional Area. Journal of Heat Transfer, 99(2), pp.180-186.

[12] Liu H., Wang J., 2011. Numerical Investigation on Synthetical Performances of Fluid Flow and Heat Transfer of Semiattached Rib-Channels. International Journal of Heat and Mass Transfer, 54(1-3), pp.575-583.

[13] Wongcharee K., Changcharoen W., Eiamsa-Ard S., 2011. Numerical Investigation of Flow Friction and Heat Transfer in A Channel With Various Shaped Ribs Mounted on Two Opposite Ribbed Walls. International Journal of Chemical Reactor Engineering, 9(1), A26.

[14] Desrues T., Marty P., Fourmigué J., 2012. Numerical Prediction of Heat Transfer and Pressure Drop in Three-Dimensional Channels with Alternated Opposed Ribs. Applied Thermal Engineering, 45-46, pp.52-63.

[15] Xie G., Li S., Zhang W., Sundén B., 2013. Computational Fluid Dynamics Modeling Flow Field and Side-Wall Heat Transfer in Rectangular RibRoughened Passages. Journal of Energy Resources Technology, 135, 042001.

[16] Marocco L., Franco A., 2017, Direct Numerical Simulation and RANS Comparison of Turbulent Convective Heat Transfer in A Staggered Ribbed Channel with High Blockage. Journal of Heat Transfer, 139(2), 021701 .

[17] Promvonge P., Thianpong C., 2008. Thermal Performance Assessment of Turbulent Channel Flows over Different Shaped Ribs. International Communications in Heat and Mass Transfer, 35(10), pp.1327-1334.

[18] Skullong S., Thianpong C., Promvonge P., 2015. Effects of Rib Size and Arrangement on Forced Convective Heat Transfer in A Solar Air Heater Channel. Heat and Mass Transfer, 51(10), pp.1475-1485.

[19] Vanaki S.M., Mohammed H., 2015. Numerical study of nanofluid forced convection flow in channels using different shaped transverse ribs. International Communications in Heat and Mass Transfer, 67, pp.176-188.

[20] Yang W., Xue S., He Y., Li W., 2017. Experimental Study On The Heat Transfer Characteristics of High Blockage Ribs Channel. Experimental Thermal and Fluid Science 83, pp.248-259.
[21] Cengel Y.A. and Cimbala J.M., 2006. Fluid Mechanics Fundamentals and Applications, International Edition, McGraw Hill Publication, 185201.

[22] Matsubara K., Ohta H., Miura T., 2016. Entrance Region Heat Transfer in A Channel with A Ribbed Wall. Journal of Heat Transfer 138(12), 122001.

[23] Anonymous, 2009. ANSYS-Fluent 12.0 Theory Guide, ANSYS Inc., USA.

[24] Yemenici O., Umur H., 2016. Experimental Aspect of Heat Transfer Enhancement over Various Flow Surfaces. Heat Transfer Engineering 37(5), pp. $435-442$ 